\title{
Why Musella lasiocarpa (Musaceae) is used in Southwest China to Feed Pigs.
}

\section{Authors: Chunlin Long, Selena Ahmed, Xiaorong Wang, Yitao Liu, Bo Long, Chunyan Yang, Yana Shi, Xingyu Li, and Rong Guo}

The final publication is available at Springer via http://dx.doi.org/10.1007/s12231-008-9013-z.

Long, Chunlin, Selena Ahmed, Xiaorong Wang, Yitao Liu, Bo Long, Chunyan Yang, Yana Shi, Xingyu Li, and Rong Guo. "Why Musella Lasiocarpa (Musaceae) Is Used in Southwest China to Feed Pigs." Economic Botany 62, no. 2 (June 2008): 182-186. doi:10.1007/ s12231-008-9013-z. 


\title{
Why Musella lasiocarpa (Musaceae) is Used in Southwest China to Feed Pigs
}

\author{
Chundin Long ${ }^{1,2}$, Selena Ahmed ${ }^{*, 1,3,4}$, Xiaorong WanG ${ }^{5}$, Yitao LiU ${ }^{1}$, \\ Bo LONG ${ }^{1,6}$, ChUNYAN YANG ${ }^{1,6}$, YANA SHI $^{1,7}$, XINGYU LI $^{1,7}$, AND Rong GUO ${ }^{1,7}$ \\ ${ }^{1}$ Kunming Institute of Botany, Chinese Academy of Sciences, Kunming, China \\ ${ }^{2}$ College of Life and Environment Sciences, Central University for Nationalities, Beijing, China \\ ${ }^{3}$ The Graduate Center of the City University of New York, New York, USA \\ ${ }^{4}$ The New York Botanical Garden, New York, USA \\ ${ }^{5}$ Laboratory of Biology, Yongzhou Vocation College, Hunan, China \\ ${ }^{6}$ Graduate School, Chinese Academy of Sciences, Beijing, China \\ ${ }^{7}$ Yunnan Agricultural University, Kunming, China \\ *Corresponding author, e-mail: selenaahmed@aol.com
}

\section{Introduction}

This study seeks to understand the usage of Musella lasiocarpa as pig fodder in southwest China by investigating its cultivation, consumption quantities, and nutrient composition. A previous report on the ethnobotany and conservation status of Musella lasiocarpa highlighted the importance of this plant for its multiple uses and services (Liu et al. 2003). The research presented here, which is a follow up effort to the previous study, is a step toward a more comprehensive exploration of the cultivation potential of Musella lasiocarpa for food and fodder in an expanded geographic area.

Musella lasiocarpa (Franch.) C. Y. Wu ex H. W. Li (Fig. 1), with synonyms of Musa lasiocarpa Franch. and Ensete lasiocarpum (Franch.) E. E. Cheesman, is a species of a monotypic genus in the Musaceae family. It is endemic to the watersheds of the Upper Yangtze River and its branches between Yunnan and Sichuan provinces in southwest China (Wu and Kress 2000). Wild populations of Musella are found around cliffs in northem Yunnan and southem Sichuan. This plant is adapted to broad ecological conditions; it is able to withstand dry, cold, and mountainous environments.

The literature on uses of Musella lasiocarpa focuses on practices by Han Chinese communi- ties and reports that it is primarily used as fodder and, to a lesser extent, in the human diet. Aside from fodder and food, our previous research in the communities of Yunnan's minority cultural groups shows that Musella is valuable for soil and water erosion control, weaving material, medicine, wine-brewing, and as a source plant for honey during the winter season (Long 1997; Liu et al. 2003). Recently, some horticulturalists from the United States, United Kingdom, European Union, and Japan have taken an interest in the commercial development of this resource as an omamental. While the chemical composition of Musella previously has been documented (Qin et al. 2000; Yang et al. 2001), no studies have reported on its nutrient content or extent of use. Given this lack of research, coupled with Musella's extensive use in southwest China and broad ecological adaptation, we investigated its cultivation, quantities consumed as pig fodder, and nutrient composition in order to understand the rationale for its usage and development potential.

\section{Methods}

\section{SuRvey ANd Study Sites}

Fieldwork was conducted in southwest China between 2003 and 2006 using participatory rural 
appraisal (PRA) methods in communities where Musella lasiocarpa has a long history of being cultivated. This includes the central Yunnan prefectures Chuxiong, Dali, Lijiang, Kunming, Yuxi, and Honghe. We furcher selected four townships in Chuxiong and Kunming as our case study sites: Qianjin, Tanhua, Xiaohe, and Hongtudi. The cultural groups in the communities studied include $\mathrm{Han}, 14$ branches of $\mathrm{Yi}$, and one branch of Miao (referred to as Hmong in countries outside of China). The Yi branches that cultivate Musella include the Axi, Azhepo, Ganyi, Lipu, Luoluopu, Luolupo, Naluo, Nasu, Naisupo, Niesupo, Nuosu, Sani, Taliu, and Talusu; the Miao branch includes the Ameng, also known as the Dahuamiao. We interviewed 213 informants (10\% of the total population) from 144 households (representing $38 \%$ of total households) at the case study sites to gather data on the Musella's cultivation systems and the amount fed to pigs annually per household compared with other fodder. Our informants include $66 \% \mathrm{Han}, 28 \% \mathrm{Yi}$, and $6 \% \mathrm{Miao}$.

The elevation of the study sites ranges from 1,570 to 2,637meters ( $\mathrm{m}$ ) above sea level and the annual rainfall fluctuates between 1,200 millimeters $(\mathrm{mm})$ and $1,800 \mathrm{~mm}$. Locals primarily follow traditional dry-land agriculture practices where they grow wheat, barley, buckwheat, corn, and other upland crops, including Musella. Some farmers manage a few areas of rice paddy fields. Pigs are valued as the most important domestic animal. Other livestock kept by local communities include goats, cattle, and buffalo.

\section{Nutrient Composition}

We collected Musella lasiocarpa individuals from Hongqiang community of Chuxiong Prefecture in November 2004 to examine the content of protein, starch, fat, other carbohydrates, and vitamin C. Plants were separated into six parts including root, hizome, pseudostem, leaf (blade and petiole), inflorescence, and fruit. Samples were randomly selected from five Musella individuals and were sliced into small pieces and dried indoors for nutritional composition analysis.

The Association of Official Analytical Chemists (AOAC) methods were used to analyze protein (method 984.13; AOAC 1990), fat (method 920.39; AOAC 1990), starch, and other carbohydrate (method 32.2.05; AOAC 1997) content of the samples. The vitamin $\mathrm{C}$ content of the samples was determined by dichlophenol indo- phenols' titration (AOAC 1984). Mineral content was analyzed by dry-ashing 3 grams (g) of lyophilized and milled Musella samples in a muffle furnace at $500^{\circ} \mathrm{C}$, and dissolving the remains in nitric acid $\left(\mathrm{HNO}_{3}\right)$ and hydrogen chloride (HCl) (AOAC 1990). Calcium (Ca), magnesium $(\mathrm{Mg})$, iron $(\mathrm{Fe})$, and zinc $(\mathrm{Zn})$ were determined by atomic absorption, potassium (K) was determined by emission spectrometry, and phosphorus $(\mathrm{P})$ was determined by a spectrophotometric ammonium molybdate method.

\section{Results}

Musella lasiocarpa is an important component of the cultivation systems at the study sites. It is cultivated primarily on the edges of terraced uplands and marginal land $(70 \%$ of Musella's cultivation area) and, to a lesser extent, in home gardens (15\%) and plantations (15\%). Approximately $45 \%$ of cultivated Musella grows in agroforestry systems, $40 \%$ grows in intercropped systems, and $15 \%$ grows in monoculture systems.

Within agro-forestry systems, Misella grows with fruit trees and crops that commonly are cultivated in Yunnan induding peach, pear, persimmon, walnut, apple, chestnut, maize, wheat, potato, rape seeds, cabbage, pea, radish, carrot, and allium. The composition in terms of area within these systems is approximately $10 \%$ Musella, 25\% fruit trees, and 65\% other crops. The palm Trachycarpus fortunei also is found in some systems. An important management characteristic of these agro-forestry systems is their associated bee-keeping practice. Chinese bees (Apis cerana cenana; Fabricius) are kept in boxes between terraces to pollinate the system's vegetation. The management of Musella is valuable for its lack of irrigation and chemical input needs because it requires no fertilizer, pesticides, or herbicides.

In the study sites, almost every household cultivates Musella in an area varying from 10 square meters $\left(\mathrm{m}^{2}\right)$ to $2,000 \mathrm{~m}^{2}$, depending on the land held by the household and the number of pigs raised. Both males and females are active in the cultivation and harvest of Musella. However, females appear to be more knowledgeable about harvest times and cultivation amounts and areas. While locals primarily grow Misella for subsistence use, it is increasingly being commercialized on a small scale as an ornamental for gardens in southwest China. We estimate that approximately 132,000 square kilometers $\left(\mathrm{km}^{2}\right)$ of territory 


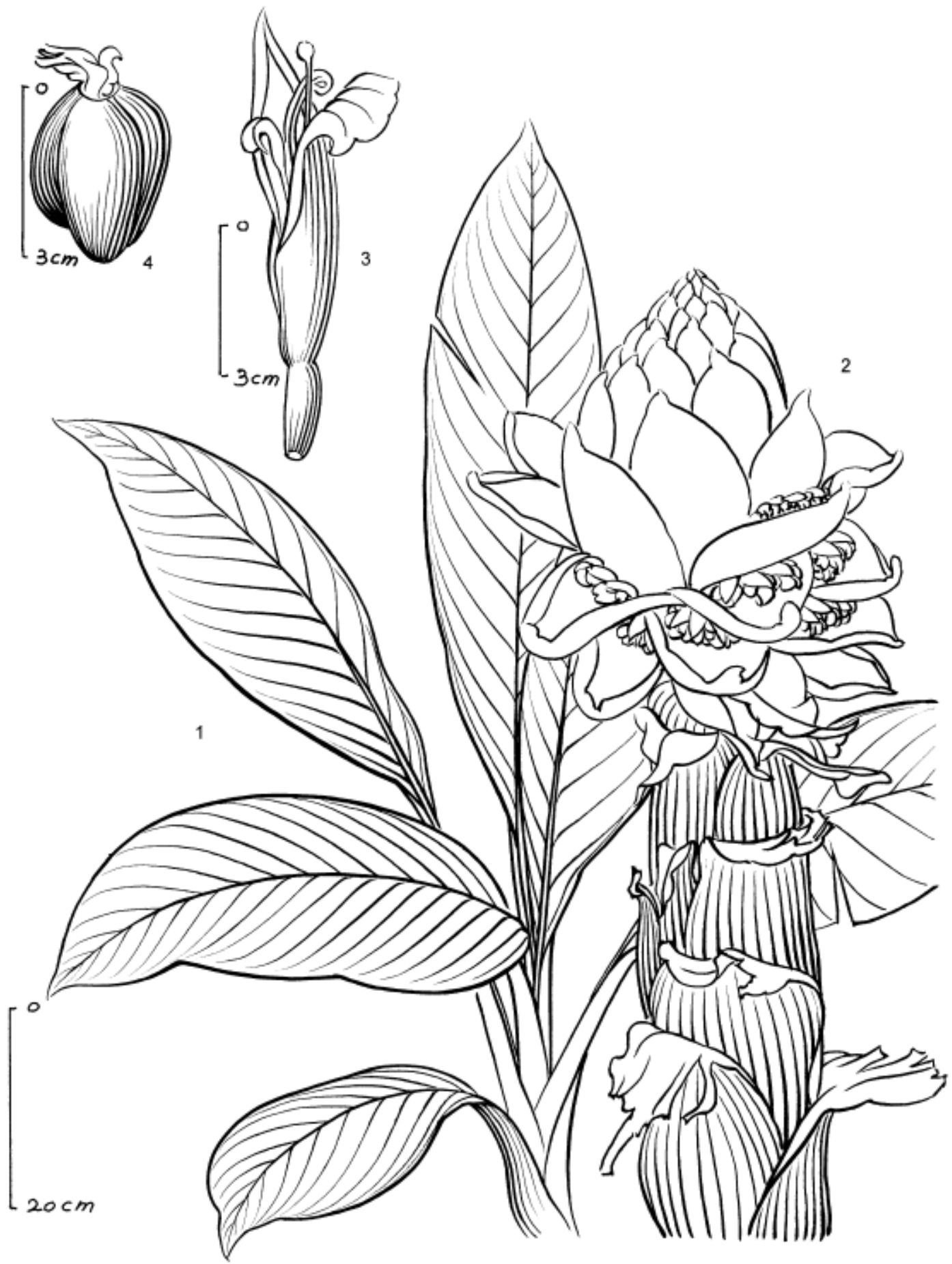

Fig, 1. Musella lasiocarpa (Franch.) C. Y. Wu ex H. W. Li 1 = Plant; 2 = Inflorescence; 3 = Male Flower; $4=$ Ovary. 
TABIE 1. NutrRiENT COMPOSTITON OF MUSELLA LASIOCARPA (FROM DRY MATERJALS).

\begin{tabular}{lccccl}
\hline \hline Category & Protein (\%) & Starch (\%) & Fat $(\%)$ & Other Carbohydrates $(\%)$ & Vitamin C (mg/100g) \\
\hline Root & 3.81 & 2.11 & 1.40 & 6.90 & 0 \\
Rhizome & 3.58 & 42.59 & 0.44 & 9.39 & 0 \\
Pseudostem & 3.92 & 53.91 & 0.51 & 7.31 & 1.20 \\
Leaf & 17.25 & 0.00 & 2.84 & 13.13 & 9.33 \\
Inflorescence & 11.42 & 0.00 & 3.36 & 13.29 & 2.33 \\
Fruit & 11.98 & 2.21 & 1.66 & 5.42 & 0 \\
\hline
\end{tabular}

throughout central Yunnan is distributed with Musella plantations, with over 10 million cultivators. Among the approximately 10 million cultivators, 8 million are Han, 1.7 million are $\mathrm{Yi}$, and 300,000 are Miao. Locals living near wild populations of Musella harvest it for fodder and cultivation material. Our research found little evidence to support which cultural group domesticated this species.

All informants interviewed indicated that the use of Musella as pig fodder improves the growth of their animals. The whole plant can be used as fodder, either raw or after being cooked. The pseudostem, leaf, and inflorescence are the primary feeding materials; occasionally the rhizome, fruits, and roots are used also. Pigs are the only animals in the study sites that are fed Musella. Results from our survey on the amount of feedstuff consumed by pigs reveal that Musella is a significant pig fodder in all communities interviewed, with a mean weight of annual usage per household ranging from 1,443.7kilograms (kg) to $2,261.6 \mathrm{~kg}$. This represents $9 \%$ to $16 \%$ of total pig fodder. Our informants indicated that they use the langest amount of Musella in the winter, the season when the inflorescences of most Musella individuals emenge, because of the plant's increased nutritional value and the shortage of other fodders during this time. Other plant material used as pig fodder in the case sites includes buckwheat and leaves of sugar beet, mustard, radish, and sweet potato. The data indicate that the proportion of different pig fodder used by households shows slight variation between cultural groups and localities, with Yi communities using the greatest amount of Musella.

Data on the nutrient composition of Musella (Table 1) show it to be a significant source of protein, fat, carbohydrates, vitamin $\mathrm{C}$, and starch. Musella leaves contain the greatest content of protein followed by the fruits and inflorescences of the plant. The leaves also contain the greatest content of vitamin $\mathrm{C}$ and its pseudostem and rhizome contain the greatest amount of starch. Analysis of the mineral composition of Musella shows that it is a significant provider of $\mathrm{K}$, comprising $3.16 \%$ of the combined dry weight of the pseudostem, leaf, and inflorescence.

\section{Conclusion}

Musella lasiocarpa can be recognized as an important forage crop in central Yunnan because of the significant proportion it represents of total fodder consumed by pigs and its availability during the winter when there is a shortage of other fodders. Our results support that Musella's rich nutrient composition is responsible for its wide cultivation by farmers in central Yunnan. In order to optimize the nutritional value of Musella, we recommend the whole plant be used to compensate for the nutrient content variation in different plant parts. For example, the lack of starch in the protein-containing leaves is compensated for by the starch content of the pseudostem. Further research is needed to address the nutritional variation our informants reported due to seasons and preparation methods. In addition, our research supports that Musellabased agro-forestry systems are multi-productive and their multi-storied vegetative structure protects the soil. Given Mtsella's nutrient composition and broad adaptation to different ecological conditions, it is an appealing crop to be incorporated into agro-forestry systems globally, particularly in Himalayan and Southeast Asian countries. This can be achieved through extension organizations and farmer-to-farmer exchange systems.

\section{Acknowledgements}

The authors would like to thank the Experimental Center of Yunnan Academy of Agricultural Sciences 
for assisting with the laboratory analysis; the Ministry of Science and Technology of China (2004 DKA30430 and 2005DKA21006), 111 Project (B08044), and the U.S. National Science Foundation for financial support; Mr. Li-tao Liu for preparing the illustration; and Dr. Charles Peters of the New York Botanical Garden for his comments on the manuscript.

\section{Literature Cited}

AOAC. 1984. Official Methods of Analysis of the Association of Official Analytical Chemists (AOAC), 14th ed. Pages 844-845 in S. Williams, ed., AOAC, Arlington, Virginia. 1990 Official Methods of Analysis of the

Association of Official Analytical Chemists (AOAC), 15th ed., vols. 1 and 2. K. Helrich, ed., AOAC, Arlington, Virginia.

1997. Official Methods of Analysis of the Association of Official Analytical Chemists (AOAC). 16th ed., 3rd revision. P. Cuniff, ed., AOAC International: Gaithersburg, Maryland.
Liu, A. Z., W. J.Kress, and C. L.Long. 2003. Customary Use and Conservational Attention to Musella lasiocarpa (Musaceae): A Monotypic Genus Endemic to China. Economic Botany $57: 2,279-281$.

Long, C. L., 1997. The Development Potential of Musella lasiocarpa. Pages 168-176 in Yunnan Association of Science and Technology, Proceedings of Workshop on Enterprises and Marketing of Special Animals and Plants in Yunnan. Kunming, China.

Qin, B., R. H.Lu, H. Q.Wang, and M.Wang. 2000. Chemical Constituents from Musella lasiocarpa (Franchet) C. Y. Wu. Natural Product Research and Development 12(2): 41-44.

Wu, D. L. and W. J. Kress. 2000. Musaceae. Pages 314-318 in C. Y. Wu and P. H. Raven, eds., Flora of China. Vol. 24 (Flagellariaceae through Marantaceae). Science Press, Beijing, China and Missouri Botanical Garden Press, St. Louis, Missouri.

Yang, W. L., J. Tian, B. R. Bai, J. F. Guan, and L S. Ding 2001. Chemical Constituents of Musella lasiocarpa. Chinese Traditional and Herbal Drugs 32(8): 681-683. 